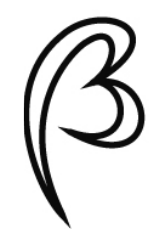

Bureau d'économie théorique et appliquée

\title{
«Fiscal decentralization and the performance of higher education institutions: the case of Europe »
}

\author{
$\underline{\text { Auteurs }}$ \\ Julien Jacqmin, Mathieu Lefebvre \\ Document de Travail $n^{\circ} 2017-31$
}

Bureau d'Économie

Théorique et Appliquée

BETA - UMR 7522 du CNRS

\section{BETA Université de Strasbourg}

Faculté des sciences économiques et de gestion

61 avenue de la Forêt Noire 67085 Strasbourg Cedex

Tél. : +33 (0)3 68852069

Fax : +33 (0)3 68852070

Secrétariat : Géraldine Del Fabbro g.delfabbro@unistra.fr

\section{BETA Université de Lorraine}

Faculté de droit, sciences

économiques

et de gestion

13 place Carnot C.O. 70026

54035 Nancy Cedex

Tél. : +33(0)3 72742070

Fax : +33 (0)3 72742071

Secrétariat : Sylviane Untereiner sylviane.untereiner@univ-lorraine.fr

Novembre 2017

http://www.beta-umr7522.fr 


\title{
Fiscal decentralization and the performance of higher education institutions: the case of Europe
}

\author{
Julien Jacqmin \\ HEC Liège and University of Liège \\ Mathieu Lefebvre \\ BETA, University of Strasbourg
}

November 2, 2017

\begin{abstract}
This paper empirically evaluates the impact of fiscal decentralization on the performance of higher education systems. To test this relationship, we build up a panel dataset composed of European countries. Countrylevel performance is measured by an indicator using data from the Shanghai ranking. Using a dynamic panel approach, we find that a higher share of government spending coming from decentralized levels of governments leads to an improvement of the performance of research-intensive higher education institutions. This result is confirmed by the use of an instrumental variable approach. We argue that a more decentralized higher education system increases the ability to attract and retain top scholars.
\end{abstract}

Keywords: fiscal decentralization, ranking, higher education institutions .

JEL codes: I23, I28, H52, H75 


\section{Introduction}

Since the Lisbon and Europe 2020 strategies, research-intensive higher education institutions are high on the european political agenda. The concomitant emergence of worldwide higher education rankings, like the Shanghai and the Times Higher Education rankings, has shown a decreasing influence of European universities, at the benefit of their american counterparts, and the emergence of top institutions in Asia. In parallel, supranational institutions such as the World Bank (World Bank [2000]) or the OECD have promoted reforms towards a greater decentralization of political powers. The goal of this paper is to study how increasing the extent of fiscal decentralization influences the performance of the higher education sector.

From a general point of view, the impact of more decentralization on production efficiency is not clearcut. According to a large part of the literature, a greater level of decentralization is beneficial for government-supported services such as health or education, thanks to the informational advantages of local governments which can provide a better match with citizen's preferences (Oates [1972]). This line of argumentation is deeply rooted in Tiebout's framework where citizen's mobility can lead to the desired amount of competition between jurisdictions by voting with their feet (Tieboult [1956]). Several mechanisms have been provided to explain this relationship. A first one comes from an improved political accountability (see Seabright [1996] or Persson and Tabellini [2000]). Decentralization closes the gap between politicians in office and citizens. The former then have more incentives to act in accordance to the latter due to this greater scrutiny. A second explanation relates to the greatest ease in comparing the benevolence of politicians by benchmarking their performances. By allowing yardstick competition between local governments, incumbent politicians are more disciplined and are better selected (Besley and Case [1995] and Belleflamme and Hindricks [2005]). A third explanation is that decentralization promotes policy innovation where each local entities pursue a different policy experiment and let the better performing policy option emerge more easily (Rose-Ackerman [1980]).

However, a greater decentralization comes at a cost. First of all, it can create efficiency losses due to the spillovers related to the public good characteristics of the services provided and the more limited economies of scale. Second, local governments can be more easily captured by local special-interest groups than national governments (Bardhan and Mookherkee [2000]).

The empirical consequences of decentralization have been a highly debated 
issue (see Baskaran et al. [2016] or Martinez-Vazquez et al. [2017] for reviews). Most of the literature has looked at its impact on issues like growth or public finance spending characteristics such as public expenditures or public debts. A more limited literature has focused on its impact on public service provision or more widely on government-regulated and funded sectors such as the health and education sector (see Blochliger et al. [2013] and Channa and Faguet [2016] for a literature review).

In the context of education, the most talked-about topic about decentralization relates to the extent of autonomy granted to schools and higher education institutions (Aghion et al. [2008]; Hanushek and Woessmann [2011]). Our paper is more directly related to works dealing with decentralization in the context of fiscal federalism, mostly by using the extent of decentralization of government expenditures ${ }^{1}$ as an independent variable. Barankay and Lockwood [2007] were the first to test the relationship between decentralization and educational attainment, as measured by the fraction of 19 years old students allowed to continue to study to university in Switzerland. They found a positive and significant relationship along various specifications. In addition they observe that decentralization has impacted relatively more male students, leading to a reduction of the gender gap in enrollment. Faguet and Sanchez $[2008,2014]$ look at the impact of decentralization on enrollment rates in public schools in two developing countries, Colombia and Bolivia. They find a positive relationship that can be explained by the higher interests of local governments for investments in such social services. Using test scores, Galiani et al. [2008] find that overall decentralization has had a positive impact in Argentina. However, this was not the case for schools located in poor communities. Closer to us, as they also use a cross-country analysis, Falch and Fischer [2012] observe that more decentralized countries tend to perform better on the PISA and TIMMS tests.

Looking at the higher education sector, the theoretical arguments just exposed seem to apply as well, especially in the European context. The impact of decentralization is a priori unclear. On the one hand, there are plenty of reasons why decentralization could lead to an improvement of the sector. First, many empirical works have shown the limited economies of scale observed in higher education. This is true at the institutional level and it is also likely at the

\footnotetext{
${ }^{1}$ This is likely to be a good proxy of regulatory autonomy as well, in the absence of data on the decentralization of the governmental regulation taking place in the sector. One reason is that most of the public funding granted comes with some strings attached to it that are set by the government granting it.
} 
country level (Cohn et al. [1989]). Second, the greatest comparability across jurisdictional borders will make the competition to attract top-researchers much fiercer and regions will try to keep/attract them. This will lead to a race to the top where they will be offered very competitive work/salary packages. As a consequence, a higher decentralization will limit a brain drain outside of the countries analyzed. Third, this is especially true as these handful of topresearch institutions will more than likely be more influential in setting higher education policies at a local rather than at a national level. Hence, they might encourage the adoption of policy innovations which are more in line with their interests.

On the other hand, public good spillovers related to the academic research output are important. Decentralization can lead to an underprovision of incentives to provide them. In our setting, following an argumentation similar to Justman and Thisse [2000] in the context of student mobility, this would lead to limited incentives to attract top researchers by providing them attractive work packages. According to this line of argumentation, decentralization would hurt the performance of the higher education sector.

Using an original dataset comparing the performance of the higher education systems in Europe, as measured by aggregating at the country-level data from the Shanghai ranking, we test if a higher decentralization of public funding granted to the sector influences the performance outcome. The main result of our paper is the following. We find that, on average, decentralization improves the performance of the higher education sector. This result is robust to various specifications and methods. First, we compute two-way fixed effects estimators adapted to a dynamic setting to account for the persistence of our dependent variable. Second, we use two instrumental variables to tackle the issue of endogeneity: the level of decentralization in the compulsory education system and the average level of decentralization in the countries with shared land borders. Finally, looking at each indicators used to build the ranking and at data from the ERC grants obtained, our results confirm the hypothesis according to which decentralization improves the ability to attract and retain top scholars and the overall performance of the sector as defined by ranking data.

The paper is organized as follows. Section 2 presents our database. Our two estimation strategies are exposed in Section 3. Section 4 presents our main results. Finally, Section 5 concludes. 


\section{Data and measures of decentralization}

We have collected an original panel dataset for a series of EU countries. We focus on European countries, as they tend to have more comparable higher education systems since the implementation of the Bologna reform. Unfortunately, we had to drop some countries due to missing data. The period under scrutiny spans from 2004 to 2014. In the end we obtained an unbalanced panel data of 163 observations for 18 countries: Austria, Belgium, Czech Republic, Denmark, Finland, France, Germany, Hungary, Ireland, Italy, Norway, Poland, Portugal, Slovenia, Spain, Sweden Switzerland and the U.K.

Our main explanatory variable is the level of public expenditure decentralization in the sector of higher education, as measured by the ratio between subnational government expenditure to total government expenditure in this sector. We rely on the OECD Education database and name it Decentralization.

Other control variables related to the higher education system, the state of the economy and the political context are also included in our model to circumvent problems related with the omitted variable bias. These data are collected from Eurostat, OECD, UNESCO and the Database of political institutions (Beck et al. [2001]). We first control for the level of investment in the higher education system coming from public sources. We use Spending in \% of GDP which measures the level of government expenditures invested as a percentage of GDP. Private is the share of students going to private tertiary education institutions. We also control for the country's economic and public finance conditions by including (the log of) GDP per capita and deficit as a percentage of GDP per capita. Finally, we control for the political context. We introduce a variable, in line with the political business cycles literature, to control for the fact that it was an election year at the national level. Finally we control for the orientation of the political forces at work with Parl. left which is the share of seats in the parliament in the hand of left wing parties.

Compared with the literature looking at the determinants of the performance of compulsory education which uses standardized test scores such as PISA (see Hanushek and Woessmann [2011] for a survey), there are no consensus among economists nor policy makers on how to measure performance in the higher education context. Previous works looking at country level data have mainly used ranking data at the institution level. Ranking are far from being uncontroversial. They are much talked about in the media, among policy markers and whithin academia. Recent works have shown that they play an important role in the local and international student's decision where to 
study (see for example Luca and Smith [2013] and Beine et al. [2014]). In line with Aghion et al. [2008] and Jacqmin and Lefebvre [2016], we aggregate information from the Academic Ranking of World Universities (ARWU), better known as the Shanghai ranking, to be able to make cross-country comparisons. We take the following steps in order to obtain an indicator of performance at the country level. As there are 500 institutions in the ranking, we give to each institutions a number equal to 500 minus its rank. We then take the sum for the institutions of each countries. This builds up sumrank our independent variable.

Before going further, it is important to detail how this Shanghai ranking is constructed. It is the aggregation of 6 indicators: alumni winning nobel prizes and fields medals (as a proxy of the quality of education), staff winning nobel prizes and fields medals, highly cited researchers in different subject categories (as proxies of the quality of faculties), papers published in Nature and Science, papers indexed in the Science Citation Index-expanded and social science citation index (as proxies of the research output) and per capita academic performance (normalized to the size of the institution). For each of these criteria, the institution with the highest score has a score of 100 and the score of other institutions is normalized to this score. The final ranking is based on the aggregate indicator obtained from the weighted sum of these 6 indicators (a weight of $10 \%$ is given to the first and last, $20 \%$ for the others). Note also that, for the two first indicators, a smaller importance is given if the alumni or faculty received an award more than one decade ago, more than two decades ago, etc. Only papers published during the 4 years before the ranking are considered. Hence, the ranking is closer to be a measure of the stock than the flow of the institutional performance. As discussed in David [2013], the Shanghai ranking is biased towards top level research-oriented institutions and favors hard sciences. However, compared with other rankings such as the Times Higher Education and the QS world university rankings, it has the advantage of using the same methodology over the years (which allows to recompute the indicator and to make comparisons across years) and in a transparent manner. Throughout the paper, it is important to have in mind these limitations of what we define as our performance measure. Due to the focus of the Shanghai ranking, the usual disclaimers prevail in drawing conclusions for the wider, highly heterogenous, higher education system. Table 1 presents summary statistics of our variables. 
Table 1: Descriptive statistics

\begin{tabular}{llcccc}
\hline \hline & & Mean & Std. dev. & Min & Max \\
\hline Performance measure & & & & & \\
& sumrank & 2534.92 & 3173.32 & 0 & 12502 \\
Explanatory variable & & & & \\
& Decentralization & 20.92 & 30.74 & 0 & 85.32 \\
Control variables & & & & \\
& Spending in \% of GDP & 1.37 & 0.26 & 0.96 & 2.50 \\
& $\begin{array}{l}\text { Private } \\
\text { Election year }\end{array}$ & 20.59 & 21.86 & 1.06 & 100 \\
& Gov. left & 0.26 & 0.44 & 0 & 1 \\
& GDP per capita & 38.66 & 37.57 & 0 & 100 \\
& Deficit & -1.95 & 5.97 & -32.30 & 18.80 \\
& & & & & \\
$N$ & & 163 & & & \\
\hline \hline
\end{tabular}

\section{Estimation Strategy}

Our aim is to estimate the impact of the degree of decentralization on higher education performance, as measured by our outcome variable sumrank. We have a panel of data for 18 countries. Our baseline approach is a dynamic panel approach that takes into account the problem related with the persistence of our dependent variable. In the section dedicated to robustness tests below we also deal with the possibility of endogeneity and rely on an instrumental variable approach.

Since the performance is not only influenced by current events but also by past achievements, we include the first lag of the dependent variable to account for persistency and slow adjustments in higher education performance. We estimate the following dynamic panel data model:

sumrank $_{i t}=\beta_{0}+\beta_{1}$ sumrank $_{i t-1}+\beta_{2}$ Decentralization $_{i t-2}+\beta_{3} X_{i t}+\theta_{t}+\rho_{i}+\epsilon_{i t}$

Where sumrank it is our higher education performance indicator for country $\mathrm{i}$ in year $\mathrm{t}$, Decentralization ${ }_{i t-2}$ is an indicator of the degree of decentralization and $X_{i t}$ are a set of control variables. It is likely that a change in the degree of decentralization takes some time before displaying effects. In our baseline estimation, we follow previous works by Jacqmin and Lefebvre [2016] and 
assume a lag of two years. We applied selection criteria to our model and both the Akaike Information Criterion (AIC) and the Schwartz Criterion (BIC) suggest to rely on two years of lags. Furthermore, a J-test for non-nested regression models confirm the choice of two lags. ${ }^{2}$ Focusing on a short number of lags means that we test the short run impact of decentralization. Unfortunately due to data constraints, we are not able to test its long run impact, but it does not mean that it is inexistent.

To ensure that we do not confound our variable of interest with countryspecific omitted variables that are constant across time or time specific omitted variables that are constant across countries, we include a series of year dummies $\theta$ and a series of country fixed dummies $\rho$. Finally $\epsilon_{i t}$ is an error term.

The model can be estimated with a standard two-way fixed effects approach (LSDV) ${ }^{3}$. However, in a dynamic panel data model the lagged dependent variable correlates with the error term, which causes downward bias of the autoregressive coefficient. On the contrary the bias on the coefficient of the independent variables is positive. While it has been shown that the bias is small when the number of period is large (Nickell [1981]), it may be problematic with a small sample as ours. Arellano and Bond [1991] propose an alternative with a Generalized Method of Moments (GMM) approach that incorporates suitable conditions for fixing identification problems related to endogenous covariates by using first-differences. They use all valid lags of the dependent variable as instruments in order to eliminate the correlation with the transformed error term and then to obtain unbiased estimates. When the dependent variable and/or the independent variables display some persistence, Blundell and Bond [1991] show that the lagged levels are often rather poor instruments for first differenced variables and it is better to include lagged levels as well as lagged differences as instruments: the so-called system-GMM estimator

However GMM estimators are well suited for large samples but suffer from poor finite sample properties for small $N$ and tend to underestimate the coefficients of the exogenous regressors. Given the low number of observations of our sample, it is necessary to look at alternative estimation methods. Judson and Owen [1999], Kiviet [1999] and Bruno [2005] rely on a standard fixed-effect estimator but use an approximation of its bias to obtain a bias-

\footnotetext{
${ }^{2}$ As a robustness test we also introduce different amount of lags but it does not change our main results. See the robustness section below.

${ }^{3} \mathrm{~A}$ Hausman test reveals that the results of the fixed-effects approach differ significantly from those of a random-effects approach.
} 
corrected estimator (LSDVc). Using simulations, Kiviet [1999] show that the bias-corrected estimator generates more accurate estimates and lower standard errors than the GMM estimators, especially with small panels. Given the property of our data set, we then employ this approach. The LSDVc estimator relies on a two-step approach in which a consistent estimator is chosen in the first stage, which can be obtained using various estimators: LSDV, Arellanobond or Blundell-Bond estimators. We use a LSDVc estimator since it has been shown to be more efficient than other alternatives (Bruno [2005]). ${ }^{4}$ The simulation study of Kiviet [1999] also shows that the bootstrap procedure for the estimation of the variance-covariance matrix outperforms the analytical ones. We follow their work and apply a bootstrap procedure for the standard errors with 200 repetitions.

\section{Results}

Table 2 and 3 illustrate the main regression results. The first column of Table 2 displays our base model. This specification only includes the lag of the dependent variable and our decentralization variable as an explanatory factor of tertiary education performance. The results indicate a rather strong path dependency of the performance since the coefficient is positive and significant. This can be explained by the various components of the ranking which are using windows of several years and give a not much smaller weight to older output. We also find a positive and significant coefficient associated with the decentralization variable.

We then improve our specification by introducing other important covariates of performance discussed in Section 2. Countries have different higher education landscapes, above all in the extent they distribute their public finances. In specification (2), we include the indicators of the educational landscape: the share of students attending a Private institution and Spending in $\%$ of GDP in the higher education sector. In order to control for the political environment, we include in specification (3) the orientation of the parliament in place (Gov. Left) as well as if it was an election year. In specification (4) we take into account differences between economic levels across countries by introducing the GDP per capita and the level of the budget deficit as a percentage of GDP.

\footnotetext{
${ }^{4}$ In the robustness tests we will present estimation results when we use the system-GMM Blundell-Bond estimator instead. It does not change our main results.
} 
Table 2: Decentralization and higher education performance

\begin{tabular}{|c|c|c|c|c|}
\hline & $\overline{(1)}$ & $\overline{(2)}$ & (3) & $\overline{(4)}$ \\
\hline Sumrank(t-1) & $\begin{array}{c}0.581^{* * *} \\
(0.025)\end{array}$ & $\begin{array}{c}0.566^{* * *} \\
(0.031)\end{array}$ & $\begin{array}{c}0.535^{* * *} \\
(0.029)\end{array}$ & $\begin{array}{c}0.523^{* * *} \\
(0.025)\end{array}$ \\
\hline Decentralization & $\begin{array}{c}5.614^{* * *} \\
(1.544)\end{array}$ & $\begin{array}{c}5.467^{* * *} \\
(1.539)\end{array}$ & $\begin{array}{c}5.337^{* * * *} \\
(1.504)\end{array}$ & $\begin{array}{c}5.601^{* * *} \\
(1.264)\end{array}$ \\
\hline Spending in $\%$ of GDP & & $\begin{array}{c}-0.133 \\
(30.192)\end{array}$ & $\begin{array}{c}42.851 \\
(30.152)\end{array}$ & $\begin{array}{c}30.694 \\
(27.802)\end{array}$ \\
\hline Private & & $\begin{array}{c}-11.573^{* * *} \\
(1.926)\end{array}$ & $\begin{array}{c}-9.488^{* * *} \\
(1.903)\end{array}$ & $\begin{array}{c}-10.970^{* * *} \\
(1.640)\end{array}$ \\
\hline Gov. left & & & $\begin{array}{c}0.887^{* * *} \\
(0.122)\end{array}$ & $\begin{array}{c}0.930^{* * *} \\
(0.102)\end{array}$ \\
\hline Election year & & & $\begin{array}{c}-39.208^{* * *} \\
(7.483)\end{array}$ & $\begin{array}{c}-39.753^{* * *} \\
(6.319)\end{array}$ \\
\hline GDP per head & & & & $\begin{array}{c}58.084^{* * *} \\
(20.276)\end{array}$ \\
\hline Deficit as a $\%$ GDP & & & & $\begin{array}{l}-1.553^{*} \\
(0.870)\end{array}$ \\
\hline$N$ & 163 & 163 & 163 & 163 \\
\hline
\end{tabular}

Adding other covariates does not change our previous results about the effect of decentralization on performance. Interestingly, there is no significant effect of the total spending on the level of performance. This suggests that performance is not especially related to the quantity of input but more to how these inputs are used. Also the countries where the private institutions are important in the landscape have a lower performance. GDP per capita appears to be positively correlated with higher education performance but the government deficit has a negative effect on performance. Political environment variables appear to matter as well.

One important step is to identify the channel through which decentralization has an influence on performance. Unfortunately, due to the unavailability of quantitative measures of reforms in the higher education system, we cannot show explicitly which reforms improve the performance of the sector. However, we can have a more detailed understanding of the impact of decentralization using other dependent variables. By looking separately at the impact on the 6 indicators used to compute the Shanghai ranking, we can better see the type of policies that are effective in improving performance. For this reason, we have computed country-level indicators which are, for each in- 
dicators, the sum of the scores obtained for the institutions of each countries. We have also looked at the number of ERC grants obtained and the spending to the sector as potential dependent variables.

In Table 4, we observe that more decentralization does have a positive and significant impact on the per capita academic performance $(P C P)$ and on the number of highly cited researchers $(\mathrm{HiC} i)$. Decentralization appears also to have a positive effect on the number of ERC grants obtained, although the coefficient is only marginally significant. These results tend to confirm the hypothesis according to which more decentralization helps attract and retain top scholars, as defined by their high level of influence and their ability to obtain the highly competitive and lucrative ERC grants. One plausible explanation of this result could be the introduction of advantageous work/salary packages and legislations created by a greater competition among regions to attract these scarce profiles. 
Table 3: Decentralization and higher education performance: Channels of performance

\begin{tabular}{lccccccccc}
\hline \hline & Ninstit & Alumni & Award & HiCi & NandS & Pub & PCP & ERC & Spending \\
\hline Dependent(t-1) & $0.664^{* * *}$ & $0.932^{* * *}$ & -0.072 & $-0.139^{* * *}$ & $0.184^{* * *}$ & $0.474^{* * *}$ & $-0.295^{* * *}$ & $1.216^{* * *}$ & $0.704^{* * *}$ \\
& $(0.089)$ & $(0.049)$ & $(0.077)$ & $(0.052)$ & $(0.026)$ & $(0.052)$ & $(0.027)$ & $(0.076)$ & $(0.066)$ \\
Decentralization & -0.038 & 0.213 & 0.976 & $0.788^{* * *}$ & -0.111 & -0.312 & $0.844^{* * *}$ & $1.011^{*}$ & 0.002 \\
& $(0.069)$ & $(0.278)$ & $(0.785)$ & $(0.291)$ & $(0.169)$ & $(0.558)$ & $(0.215)$ & $(0.653)$ & $(0.032)$ \\
Spending in \% of GDP & 0.808 & -3.971 & 25.020 & -6.464 & $11.316^{* * *}$ & 14.087 & $52.419^{* * *}$ & -5.885 & - \\
& $(1.616)$ & $(7.284)$ & $(20.886)$ & $(6.434)$ & $(3.816)$ & $(12.611)$ & $(5.643)$ & $(27.644)$ & \\
Private & -0.078 & 0.119 & 0.949 & $-0.836^{* *}$ & $-0.547^{* *}$ & $-3.586^{* * *}$ & 0.364 & 0.224 & 0.007 \\
& $(0.092)$ & $(0.353)$ & $(1.044)$ & $(0.351)$ & $(0.223)$ & $(0.734)$ & $(0.277)$ & $(1.106)$ & $(0.026)$ \\
Gov. left & 0.001 & -0.033 & 0.089 & 0.003 & $0.076^{* * *}$ & -0.000 & $0.159^{* * *}$ & 0.022 & -0.000 \\
& $(0.006)$ & $(0.023)$ & $(0.065)$ & $(0.023)$ & $(0.014)$ & $(0.046)$ & $(0.017)$ & $(0.089)$ & $(0.002)$ \\
Election year & -0.121 & -0.258 & -5.255 & -2.126 & $-2.567^{* * *}$ & 3.405 & $-9.757^{* * *}$ & -1.404 & 0.007 \\
& $(0.303)$ & $(1.261)$ & $(3.621)$ & $(1.413)$ & $(0.868)$ & $(2.717)$ & $(1.030)$ & $(4.716)$ & $(0.101)$ \\
GDP per head & 0.000 & -0.000 & $-27.700^{*}$ & $0.001^{* * *}$ & $8.005^{* * *}$ & $0.000^{* *}$ & $7.510^{*}$ & -40.786 & -0.000 \\
& $(0.000)$ & $(0.000)$ & $(15.436)$ & $(0.000)$ & $(2.796)$ & $(0.000)$ & $(4.164)$ & $(30.660)$ & $(0.000)$ \\
Deficit as a \% GDP & -0.007 & -0.128 & $-2.020^{* * *}$ & $1.748^{* * *}$ & 0.061 & -0.245 & $-1.157^{* * *}$ & -0.515 & -0.007 \\
& $(0.048)$ & $(0.184)$ & $(0.530)$ & $(0.189)$ & $(0.118)$ & $(0.383)$ & $(0.142)$ & $(0.658)$ & $(0.016)$ \\
\hline$N$ & 163 & 147 & 147 & 163 & 163 & 163 & 147 & 96 & 246 \\
\hline \hline
\end{tabular}

Standard errors in parentheses. ${ }^{*} p<0.1,{ }^{* *} p<0.05,{ }^{* * *} p<0.01$

Notes: Corrected-bias estimator with an initial LSDV estimate and 200 bootstrap repetitions.

GDP is taken in logarithm except for Alumni and Pub 


\section{Robustness tests}

In order to test the validity of our results, we conduct a series of robustness tests. First, we look at the dynamics of our effect by looking at other lags and average effects as well as interaction effects. We also test the validity of our results with respect to different subsamples and when we rely on another type of dynamic panel estimator. Finally, as we explained above, our results may be plagued with endogeneity issues related to the use of our measure of decentralization. We present estimations using an IV approach to tackle the problem.

\subsection{Dynamics of the effects}

One important assumption behind our first estimations is that the level of decentralization has a linear impact on performance two years after it is implemented. Statistical tests exposed above make us confident that the results are robust but there is no clear intuition that it is actually the case. In Table 4, we test different specifications with regards to the decentralization variable. First we test if there is also a significant effect if we introduce more or less lags. The first two columns of Table 4 show that the effect of decentralization has some persistence since it may affect the performance of higher education one and three years after it is implemented. Unfortunately, adding more lags between our two variables of concern reduces the number of observations considered. We can then also think that it is better to take the average of past years instead of a lag. Following Barankay and Lockwood (2007), Table 3 shows the results when we use an average of decentralization over the last five years instead of a lagged variable. Here again the results are significant. In a final step we test the non-linearity of the effect of decentralization and show that there are diminishing returns associated to decentralization. However, as the maximum of the estimated quadratic relationship is bigger than 100, the higher reachable level of decentralization, more decentralization always improves our measure of performance.

\subsection{Estimator, sample and interactions}

In additional robustness checks, exposed in Table 4, we also report estimations using the system-GMM estimator developed by Blundell and Bond [1991]. This extended GMM approach is preferred to the more commonly-used Arellano- 
bond estimator if the dependent variable displays some persistence. We find that our main results are robust to this alternative.

We also compute our estimates on the limited sample of EU15 countries. Our initial sample is made of very different countries and some of them have experienced important changes along the time period of interest. Especially, eastern countries maybe outliers since they have completely reviewed their institutions and their education system since the end of the iron curtain. When we limit the sample to those countries of the EU15, we obtain similar results than those presented in Table 2. Our estimations so far are based on an unbalanced sample, as some variables are not available in all years for all countries. We replicate our main analysis for a fully balanced sample of 17 countries for 7 years (2005-2011). Again the results are qualitatively similar.

Finally, since we have a panel of countries with different economic situations, we look at it as if there is a significant interaction between the level of available means and the level of decentralization. The idea is too look if decentralizing works better when the public resources invested in higher education are higher. Overall, we find that all these robustness checks confirm our initial results, that more decentralization positively impact the performance of the higher education sector, as measured by our indicator. In a final regression, the coefficient for decentralization*GDP/cap is significant so that we can make the claim that this effect is stronger when the level of public spending in higher education institutions is higher. 
Table 4: Robustness checks

\begin{tabular}{|c|c|c|c|c|c|c|c|c|}
\hline \multirow[t]{2}{*}{ With respect to } & \multicolumn{4}{|c|}{ Decentralization } & \multirow{2}{*}{$\begin{array}{c}\text { Estimation } \\
\text { Blundell/Bond }\end{array}$} & \multicolumn{3}{|c|}{ Sample } \\
\hline & 1 lags & 3 lags & Average & Non-linear & & EU15 & $\begin{array}{c}\text { Balanced } \\
\text { Panel }\end{array}$ & $\begin{array}{l}\text { Spending } \\
\text { Interaction }\end{array}$ \\
\hline Sumrank(t-1) & $\begin{array}{c}0.523^{* * *} \\
(0.025)\end{array}$ & $\begin{array}{c}0.526^{* * *} \\
(0.026)\end{array}$ & $\begin{array}{c}0.570^{* * *} \\
(0.035)\end{array}$ & $\begin{array}{l}0.515^{* * *} \\
(0.025)\end{array}$ & $\begin{array}{c}0.864^{* * *} \\
(0.042)\end{array}$ & $\begin{array}{c}0.490^{* * *} \\
(0.044)\end{array}$ & $\begin{array}{c}0.334^{* * *} \\
(0.035)\end{array}$ & $\begin{array}{c}0.527^{* * *} \\
(0.030)\end{array}$ \\
\hline Decentralization & $\begin{array}{c}5.624^{* * *} \\
(1.482)\end{array}$ & $\begin{array}{c}8.895^{* * *} \\
(1.542)\end{array}$ & $\begin{array}{c}12.439^{* * *} \\
(2.966)\end{array}$ & $\begin{array}{c}19.847^{* * *} \\
(3.102)\end{array}$ & $\begin{array}{c}12.281^{* *} \\
(5.972)\end{array}$ & $\begin{array}{c}21.089^{* * *} \\
(4.210)\end{array}$ & $\begin{array}{c}15.805^{* * *} \\
(3.531)\end{array}$ & $\begin{array}{c}10.693^{* * *} \\
(3.316)\end{array}$ \\
\hline Decentralization (squared) & & & & $\begin{array}{c}-0.149^{* * *} \\
(0.030)\end{array}$ & & & & \\
\hline Decentralization*GDP/cap & & & & & & & & $\begin{array}{c}-0.475^{*} \\
(0.285)\end{array}$ \\
\hline Spending in $\%$ of GDP & $\begin{array}{c}25.774 \\
(27.338)\end{array}$ & $\begin{array}{c}26.519 \\
(30.851)\end{array}$ & $\begin{array}{c}-94.440^{* *} \\
(44.844)\end{array}$ & $\begin{array}{c}108.934^{* * *} \\
(31.145)\end{array}$ & $\begin{array}{c}-5.579 \\
(259.421)\end{array}$ & $\begin{array}{l}-46.956 \\
(51.550)\end{array}$ & $\begin{array}{l}-64.813^{*} \\
(34.161)\end{array}$ & $\begin{array}{c}25.583 \\
(33.540)\end{array}$ \\
\hline Private & $\begin{array}{c}-10.958^{* * *} \\
(1.654)\end{array}$ & $\begin{array}{c}-10.463^{* * *} \\
(1.929)\end{array}$ & $\begin{array}{c}-7.790^{* *} \\
(3.890)\end{array}$ & $\begin{array}{c}-10.566^{* * *} \\
(1.606)\end{array}$ & $\begin{array}{c}13.550^{* * *} \\
(4.745)\end{array}$ & $\begin{array}{c}-14.748^{* * *} \\
(3.151)\end{array}$ & $\begin{array}{l}-11.902^{* * *} \\
(2.497)\end{array}$ & $\begin{array}{c}-11.044^{* * *} \\
(1.982)\end{array}$ \\
\hline Gov. left & $\begin{array}{c}0.922^{* * *} \\
(0.110)\end{array}$ & $\begin{array}{c}0.882^{* * *} \\
(0.117)\end{array}$ & $\begin{array}{c}0.888^{* * *} \\
(0.207)\end{array}$ & $\begin{array}{c}0.893^{* * *} \\
(0.100)\end{array}$ & $\begin{array}{l}-1.429 \\
(0.895)\end{array}$ & $\begin{array}{c}1.113^{* * *} \\
(0.179)\end{array}$ & $\begin{array}{c}1.695^{* * *} \\
(0.155)\end{array}$ & $\begin{array}{c}0.928^{* * *} \\
(0.122)\end{array}$ \\
\hline Election year & $\begin{array}{c}-40.081^{* * *} \\
(6.229)\end{array}$ & $\begin{array}{c}-38.691^{* * *} \\
(7.130)\end{array}$ & $\begin{array}{c}41.886 \\
(41.281)\end{array}$ & $\begin{array}{c}-38.352^{* * *} \\
(6.185)\end{array}$ & $\begin{array}{l}-48.223 \\
(48.207)\end{array}$ & $\begin{array}{c}-66.091^{* * *} \\
(12.077)\end{array}$ & $\begin{array}{c}-23.785^{* * *} \\
(8.689)\end{array}$ & $\begin{array}{c}-39.910^{* * *} \\
(7.549)\end{array}$ \\
\hline GDP per head & $\begin{array}{c}57.756^{* * *} \\
(22.324)\end{array}$ & $\begin{array}{l}46.594^{*} \\
(25.479)\end{array}$ & $\begin{array}{c}8.553 \\
(22.029)\end{array}$ & $\begin{array}{c}58.242^{* * *} \\
(19.890)\end{array}$ & $\begin{array}{l}-420.813^{*} \\
(225.519)\end{array}$ & $\begin{array}{c}54.011 \\
(58.118)\end{array}$ & $\begin{array}{c}156.277^{* * *} \\
(30.961)\end{array}$ & $\begin{array}{c}9.777 \\
(38.800)\end{array}$ \\
\hline Deficit as a \% GDP & $\begin{array}{l}-1.656^{*} \\
(0.882)\end{array}$ & $\begin{array}{l}-1.452 \\
(0.951)\end{array}$ & $\begin{array}{c}-8.524^{* * *} \\
(2.170)\end{array}$ & $\begin{array}{l}-0.367 \\
(0.908)\end{array}$ & $\begin{array}{c}9.426 \\
(8.314)\end{array}$ & $\begin{array}{l}-3.168^{*} \\
(1.631)\end{array}$ & $\begin{array}{c}-2.803^{* * *} \\
(1.082)\end{array}$ & $\begin{array}{l}-0.677 \\
(1.200)\end{array}$ \\
\hline Constant & & & & & $\begin{array}{c}6835.845^{* * *} \\
(2499.365)\end{array}$ & & & \\
\hline$N$ & 163 & 163 & 163 & 163 & 141 & 113 & 127 & 163 \\
\hline
\end{tabular}

Standard errors in parentheses. ${ }^{*} p<0.1{ }^{* *} p<0.05,{ }^{* * *} p<0.01$

Notes: Corrected-bias estimator with an initial LSDV estimate and 200 bootstrap repetitions. GDP is taken in logarithm. 


\subsection{Endogeneity issues}

Our dynamic panel approach allows to control for year- and country- specific characteristics thanks to the year and country fixed effects. However, it is still possible that a third variable which is varying across time and places is both related with our explanatory variable and the dependent variable of our model. ${ }^{5}$ This issue could give rise to endogeneity, leading to biased coefficients. One way to tackle this issue is to use instrumental variables, variables unrelated with our dependent variable but related with our explanatory variable.

In our panel context, the main challenge is to find suitable instruments that vary both over countries and years, as instruments commonly used in analyzing the consequences of institutional characteristics are static or are not adequate to our European sample. ${ }^{6}$ Using lagged values of the endogenous variable (as in Enikolopov and Zhuravskaya [2007]) is also unlikely to be a good strategy in our context as the impact of decentralization is not contemporaneous and can both take place in the short and the long run. As claimed by recent surveys of the literature (Channa and Faguet [2016] and MartinezVazquez et al. [2017]), the use of time-variant exogenous instruments to endogenize the decentralization variables has been to date limited and mostly unsatisfactory.

We use two instruments: decentralization of public expenditures in compulsory education and the average level of decentralization of higher education in the nearby countries, as defined by countries with whom it shares a land border. In addition, to replace the latter instrument, we also use the level of decentralization in the country who's capital city is the closest to the capital of the instrumented country.

The economic logic behind the use of decentralization of public expenditures in compulsory education is that it is likely to be correlated with the one at the tertiary level. These two sectors tend to be closely related and preferences about the level of decentralization are likely to be very similar. This is particularly true in Europe where, in most cases, the two sectors are even headed by the same minister (Jacqmin and Lefebvre [2016]). On the other hand, in the short and medium run, this measure of decentralization is unlikely to be related with our performance measure of the higher education sector. The

\footnotetext{
${ }^{5} \mathrm{~A}$ side effect of considering time lags between our explanatory and our dependent variable is that it undermines the presence of reverse causality, another source of endogeneity.

${ }^{6}$ We think for example of geographical (latitude, longitude, country size, density, etc) or historical instruments (such as settlers mortality, legal origin ) etc.
} 
only potential channel between these two variables is in the very long run. By affecting the quality of young students, a higher decentralization of public spendings directed to compulsory education could improve the performance of the higher education system by letting emerge future influential scholars.

Table 5: Instrumental variable

\begin{tabular}{lcc}
\hline \hline & IV1 & IV2 \\
\hline Sumrank(t-1) & $0.512^{* * *}$ & $0.535^{* * *}$ \\
Decentralization IV & $(0.042)$ & $(0.055)$ \\
& $35.406^{* * *}$ & $61.732^{*}$ \\
Spending in \% of GDP & $(11.532)$ & $(31.304)$ \\
& -58.138 & -150.064 \\
Private & $(57.696)$ & $(156.750)$ \\
& $-12.185^{* * *}$ & $-9.250^{* *}$ \\
Gov. left & $(2.852)$ & $(4.261)$ \\
& $0.813^{* * *}$ & 0.518 \\
Election year & $(0.198)$ & $(0.391)$ \\
& $-40.105^{* * *}$ & $-39.948^{* * *}$ \\
Log(GDP per capita) & $(10.000)$ & $(14.959)$ \\
& $136.573^{* * *}$ & $136.241^{* *}$ \\
Deficit as a \% GDP & $(41.619)$ & $(62.336)$ \\
& $-3.185^{* *}$ & -3.799 \\
$N$ & $(1.502)$ & $(2.810)$ \\
First stage (Cragg-Donald) F statistic & 151 & 151 \\
Anderson-Rubin Wald test (p-value) & 8.126 & 9.072 \\
\hline \hline
\end{tabular}

Standard errors in parentheses. ${ }^{*} p<0.1,{ }^{* *} p<0.05,{ }^{* * *} p<0.01$

Notes: Corrected-bias estimator with an initial LSDV estimate and 200 bootstrap repetitions. GDP per capita is taken in logarithm.

The second type of instrument is the level of decentralization of higher education of the neighbouring european countries. This instrument finds its motivation in the economic geography literature (see Cassette and Paty [2010] using decentralization policies). It is related with the idea that policies can be very contagious across countries as a consequence of strategic interactions among governments and improved information about the consequences of reforms implemented abroad. In this case we a priori can also rule out a violation of the exclusion restriction as what happens in a nearby country in term of decentralization is unlikely to affect the performance of the higher education system, as it is not a zero sum game played between only 2 countries. To support this economic intuition, we also applied the usual tests, both of which confirm the quality of these instruments. This last instrument is taken in two different ways: either the level of decentralization in the country who's capi- 
tal city is the closest to the capital of the instrumented country or the average level of decentralization in countries with shared land borders.

The advantage of having more instruments than endogenous variables it to to back-up our confidence towards the choice of our instruments with statistical tests. The results using this instrumental variable approach are exposed in Table 5. First, the Cragg-Donald F statistic of 8.1 and 9.1 in both specifications tells that we can reject with confidence the assumption of weak instruments following Stock and Yogo's critical values. Second, according to the Sargan test, our instrumental variables are valid as well. Hence, our two instruments are closely related to our endogenous variable but are only indirectly related with our dependent variable, via a change in decentralization. This is in line with the intuition exposed beforehand when exposing our estimation strategy. We see that the estimated coefficient of decentralization is positive and significant, even though the level of significance drops from the $5 \%$ to $10 \%$ threshold level when we rely on the average level of decentralization instead of the one in the closest country.

\section{Conclusion}

The goal of this paper was to study the impact of fiscal decentralization on the performance of the higher education sector. For this purpose, we crossed data on the share of government expenditures coming from the decentralized levels of government and a country-level performance indicator computed from the Shanghai ranking. Following various specifications and estimation methods, we find that more decentralization reforms are an effective tool to improve the performance of research-intensive higher education institutions.

Three issues are next on the research agenda. The first is related to the mechanism explaining this improvement in performance. Our analysis was only able to show that decentralization does not lead to more funding from public sources but to changes in labor market conditions such that there are more top scholars that are hired. Unfortunately, we could not test explicitly this assumption. A second limitation is linked with our measure of decentralization which is related with government spendings. Further robustness checks should widen this definition to consider how the decision power is shared between centralized and decentralized decision-makers. A final open question relates to the role played by the European Research Council, established in 2007 as a major source of funding for top scholars in Europe. By 
being able to internalize the spillovers observed in the sector, this supranational institution has potentially made decentralization more effective. Hence, it would be interesting to further investigate whether our results are conditional on the emergence of this institution. However, to be able to further study these three issues, data availability will likely be a key issue. 


\section{References}

Aghion, P., M. Dewatripont, C. Hoxby, A. Mas-Colell and A. Sapir, "Higher aspirations: An agenda for reforming european universities," Technical Report, Bruegel blueprint, 2008.

Arellano, M. And S. Bond, "Some Tests of Specification for Panel Data: Monte Carlo Evidence and an Application to Employment Equations," Review of Economic Studies 58 (1991), 277-297.

BARANKAY, I. AND B. LOCKWOOD, "Decentralization and the productive efficiency of governement: Evidence from Swiss Cantons," Journal of Public Economics 91 (2007), 1197-1218.

BARDHAN, P. AND D. MOOKHERKEe, "Capture and governance at local and national levels," American Economic Review 90 (2000), 135-139.

BASKARAN, T., L. FELD AND J. SCHNELlENBACH, "Fiscal federalism, decentralization, and economic growth: A meta-analysis," Economic Inquiry 54 (2016), 14451463.

Beck, T., G. Groff, P. KeEFer And P. WALsh, "New tools in comparative political economy: The database of politcal institutions," World Bank Economic Review 15 (2001), 165-176.

Beine, M., R. NOel AND L. Ragot, "Determinants of the international mobility of students," Economics of Education review 41 (2014), 40-54.

Belleflamme, P. AND J. HindRICKS, "Yardstrick competition and political agency problems," Social choice and welfare 24 (2005), 155-169.

Besley, T. AND A. CASE, "Incumbent behavior: Vote seeking, tax setting and yardstick competition," American Economic Review 85 (1995), 25-45.

Blochliger, H., B. Egert AND K. Bonesmo Fredriksen, "Fiscal federalism and its impact on economic activity, public investment and the performance of educational systems," OECD Economics department working papers (2013).

BLUNDELL, R. AND S. BOND, "Initial conditions and moment restrictions in dynamic panel data models," Journal of Econometrics 87 (1991), 115-143.

BRUNO, G. S., "Approximating the bias of the LSDV estimator for dynamic unbalanced panel data models," Economics Letters 87 (2005), 361-366.

Cassette, A. And S. PAty, "Fiscal decentralization and the size of government: a European country empirical analysis," Public Choice 143 (2010), 173-189. 
Channa, A. AND J.-P. FAguet, "Decentralization of Health and Education in developing countries: A quality-adjusted review of the empirical literature," World Bank Research Observer (2016).

COHN, E., S. RHINE AND M. SANTOS, "Institutions of higher education as multiproduct firms: Economies of scale and scope," Review of Economics and Statistics 71 (1989), 284-290.

DAVID, Q., "Determinants of research production at top US universities," B.E. journal of economic analysis and policy 13 (2013), 81-109.

ENIKOLOPOV, R. AND E. ZHURAVSKAYA, "Decentralization and political institutions," Journal of Public Economics 91 (2007), 2261-2290.

FAGUET, J.-P. AND F. SANCHEZ, “Decentralization's effects on educational outcomes in Bolivia and Colombia," World Development 36 (2008), 1294-1316.

_ _Decentralization and access to social services in Colombia," Public choice 160 (2014), 227-249.

FALCH, T. AND J. FISCHER, "Public sector decentralization and school performance: International evidence," Economic letters 114 (2012), 276-279.

Galiani, S., P. Gertler AND E. Schargrodsky, "School decentralization: Helping the good get better, but leaving the poor behind," Journal of Public Economics 92 (2008), 2106-2120.

HANUSHEK, E. AND L. WOESSMANN, “The economics of international differences in educational achievement," in Handbook $f$ the economics of education (elsevier, 2011).

JACQMIN, J. AND M. LEFEBVRE, “Does sector-specific experience matter? The case of European higher education minister," Research Policy 45 (2016), 987-998.

JUDSON, R. A. AND A. L. OWEN, “Estimating dynamic panel data models: a guide for macroeconomists," Economics Letters 65 (1999), 9-15.

Justman, M. AND J.-F. THISSE, "Local public funding of higher education when skilled labor is imperfectly mobile," International tax and public finance 7 (2000), 247258.

KIVIET, J., "Expectations of expansions for estimators in a dynamic panel data model; some results for weakly exogenous regressors," in C. Hsiao, K. Lahiri, L. Lee and M. Pesaran, eds., Analysis of Panels and Limited Dependent Variable Models (Cambridge: Cambridge University Press, 1999). 
LUCA, M. AND J. SMITH, "Salience in quality disclosure: Evidence from the US News college rankings," Journal of Economics and Management Strategy 22 (2013), 58-77.

Martinez-Vazquez, J., S. Lago-Penas and A. SAcchi, "The Impact of Fiscal Decentralization: A Survey," Journal of economic surveys 31 (2017), 1095-1129.

Nickell, S. J., "Biases in Dynamic Models with Fixed Effects," Econometrica 49 (November 1981), 1417-26.

OATES, W., Fiscal federalism (Harcourt Brace Jovanovich, 1972).

Persson, T. And G. TABellini, Political economics: explaining economic policy (Cambridge: MIT Press, 2000).

ROSE-ACKERMAN, S., "Risktaking and reelection: does federalism promote innovation?," Journal of legal studies 9 (1980).

SEABRIGHT, P., "Accountability and decentralization in government: an incomplete contracts model," European Economic Review 40 (1996), 61-89.

Tieboult, C., "A pure theory of local expenditures," Journal of political economy 64 (1956), 416-424.

WORLD BANK, "Entering the 21st Century, World Development Report," Technical Report, World bank, 2000. 